\title{
Conservation of cannonball underwater heritage in the shipwreck from the sea Batavia Jakarta Indonesia
}

Riyanto ( $\nabla$ riyanto@uii.ac.id)

Universitas Islam Indonesia https://orcid.org/0000-0002-0946-7112

Muhammad Malthuf Jazuli

Universitas Islam Indonesia

Imam Sahroni

Universitas Islam Indonesia

M. Miqdam Musawwa

Universitas Islam Indonesia

Nahar Cahyandaru

Universitas Borobudur

\section{Endang Tri Wahyuni}

Universitas Gadjah Mada

Research article

Keywords: conservation, materials, iron, cannonball, underwater, heritage

Posted Date: February 13th, 2020

DOI: https://doi.org/10.21203/rs.2.23472/v1

License: (9) (i) This work is licensed under a Creative Commons Attribution 4.0 International License.

Read Full License 


\section{Abstract}

Borobudur Conservation Center Magelang, Central Java Indonesia, has received underwater cannonball heritage in the shipwreck from the sea Batavia Jakarta Indonesia. This heritage is a shipment from the Directorate for the Preservation of Cultural Heritage and the Destruction of the Indonesian Ministry of Education and Culture. This study aims to the conservation of underwater cannonball before being stored in a museum. Removal of the protective cover crust of iron artifacts without the correct and proper method can cause the more quickly the process of corrosion. To prevent this more damaging, the conservation of artifacts in the right solution is necessary. This research aims to stop the process of corrosion and conserve objects of iron in aqueous alkali corrosion potential measurement through there. Conservation of this research was conduct in four stages. The first stage is the identification of weathering, and the second stage is the analysis and characterization of surface corrosion object using the handy microscope, XRD ( $x$-ray Diffraction), XRF ( $x$-ray Fluorescence), and SEM (Scanning Electron Microscopy). The third stage is the passivation/deactivation process of corrosion using sodium hydroxide, soap water and kaffir lime water. The fourth stage is stabilization/coating of materials iron cannonball underwater heritage as soon as possible using microcrystalline wax so as not further corrosion process going so that this stage should be able to complete the conservation problems of the object until they can last for the long term. Characterization of dry and wet activated corrosion using XRD obtained mineral akaganeite. Akaganeite minerals showed active corrosion containing high concentrations of $\mathrm{Cl}$ atoms for dry and wet activated corrosion $66.603 \%$ and $64.963 \%$, respectively. After being conserved with several steps and using $\mathrm{NaOH}$, soap water and kaffir lime water show inactive corrosion. Based on the results of analysis with XRF cannonball does not contain $\mathrm{Cl}$ and Fe content reaches $98.99 \%$. The conservation method used in this research is excellent and appropriate to conserve the objects of cultural heritage cannonball material underwater iron heritage.

\section{Introduction}

Indonesia is an archipelago with thousands of islands that stretches that have varied cultures. That diversity produces variegated cultural heritage remains, either in the form of objects, structures, buildings, sites, and other heritage areas. Based on the material aspects, it is constituting then differentiated into cultural heritage in stone, brick, wood, metal, and more. So that future generations can enjoy the culture in conditions that are whole and complete, then cultural heritage must be preserved. In the preservation of cultural heritage, the conservation actions needed [1].

As an archipelago country, Indonesia is also a maritime country with a broader sea region of the land. The history of the nation of Indonesian pointed out that the marine culture of coloring a long journey the Malay Archipelago. This area was an important trade route for a very long time, especially commodity spices [1]. The current marine transportation area allows high Nusantara to store a wealth of relics from the past. The richness of the underwater remains of the sunken ship (shipwreck), along with the charge amounted to very much and scattered in various locations known or unknown. In addition to the sinking ship sea of Indonesia also stores a wealth of other underwater heritage such 
as aircraft and other war remnants. Fig. 1 showed the geological location of shipwreck materials iron cannonball.

The underwater heritage of constituent materials also varies greatly, ranging from wood, metal, ceramics, and other materials. Underwater heritage has a value significant to history, culture, and science so that it can define as a cultural heritage. Underwater heritage has an amount meaningful to history, culture, and science so that it has described as a cultural heritage. The preservation of the cultural heritage of the underwater heritage is essential to do because of the high value of significant cultural heritage and generally are in a condition that is already obsolete.

Economically underwater relics also high value so that it is on the other side is a threat to its protection [2]. Marine heritage conservation has its characteristics and degree of difficulty compared with the cultural heritage in general. Damage and weathering occur underwater relics by chemical reactions in the water, and other factors

are primarily biological activity. The method of conservation for cultural reserve land cannot directly apply to the underwater cultural heritage. The conservation method for underwater relics must pay attention to the characteristics of materials and weathering that occurs. Handling of underwater relics conservation should also have planned to range from before the adoption, at the time of appointment, and for its transport. Plan the placement of artifacts after protection is also a concern in the determination of methods of conservation. The researchers have done for the development of methods of conservation of underwater heritage currently still have to continue to do [3].

The most striking feature of the corrosion of iron in the underwater environment (sea) is the formation of a thick concretion. Concrete formed on iron buried beneath the seafloor and exposed to seawater. Concrete created by the iron corrosion products that interact with the material adjacent to the iron. Iron is not toxic, and biological materials organisms quickly attacked each iron sinks in seawater. These organisms to build layers of bone material, mainly calcium carbonate $\left(\mathrm{CaCO}_{3}\right)$. Further diffusion of iron II $\left(\mathrm{Fe}^{2+}\right)$ ions and iron III ion $\left(\mathrm{Fe}^{3+}\right)$ iron corrosion of the underlying chemical change in biological materials. In concretion, $\mathrm{Fe}^{2+}$ ions are swapped with calcium ions $\left(\mathrm{Ca}^{2+}\right)$ to produce $\mathrm{CaCO}_{3}$ or iron carbonate $\left(\mathrm{FeCO}_{3}\right)$ siderite. Some of $\mathrm{CaCO}_{3}$ also interact with hydrogen ions $\left(\mathrm{H}^{+}\right)$to form calcium bicarbonate $\left[\mathrm{Ca}\left(\mathrm{HCO}_{3}\right)_{2}\right]$ that causes increases in the $\mathrm{pH}$ of the solution. Increasing the $\mathrm{pH}$ and then generate the gradual settling of $\mathrm{Fe}^{2+}$ and $\mathrm{Fe}^{3+}$ as oxides, oxide hydrated chloride, and hydroxide. This process of filling holes and pores in concretion and so form a cementing matrix of iron to replace the original pattern of calcite, which slowly dissolves [2]. In crystallization, in the areas of low oxygen content, the reaction between the iron ions and sulfide $\left(S^{2}\right)$ ion is produced by sulfate generate the formation of iron (II) sulfide (FeS) and the element sulfur [2].

\section{Research aim}


In this paper, the present of the conservation of underwater cannonball heritage. Removal of the protective cover crust of iron artifacts without the correct and proper method can cause the more quickly the process of corrosion. To prevent this more damaging, the conservation of artifacts in the right solution is necessary. This research aims to stop the process of corrosion and conserve objects of iron in aqueous alkali corrosion potential measurement through there.

\section{Material And Methods}

\section{Identification of samples}

The object examined was the iron cannonball underwater cultural remnants taken from the sea Batavia/Jayakarta, Indonesia (Fig.1.). Identification rates of weathering can do by comparing and pay attention to every object that is experiencing active corrosion, which is characterized by the emergence of new rust (such as details of fluid). Objects that are undergoing activity corrosion grouped and sequenced implementation of appropriate levels of handling corrosion activity. Identification of the material weathering iron relics underwater observation is made by visually.

\section{Analysis and characterization of surface cannonball material iron remains an underwater culture}

The study and characterization of existing components in the sample used X-ray Diffraction (XRD) B8 Fokus and x-ray fluorescence (XRF) Portable Olympus, as for the analysis of surface corrosion object used Handy Microscope Rohs (HMR) and Scanning Electron Microscopy (SEM) Jeol JSM-T300.

\section{Passivation/deactivation corrosion}

Cannonball material iron immersed in a solution of sodium carbonate $5 \%$ (Fig.2.). The $\mathrm{pH}$ maintained at the alkaline condition at range 11-13. If the $\mathrm{pH}$ goes down, then it should be raised on the field with a solution of sodium hydroxide. Soaking was doing about one week, then rinsed with water proceeds distillation water. The next object is dried and viewed its development if it still happens, then the corrosion process is repeated. Before the process is complete, the passivation not to do cleanup crust or rust, the coating would be a natural protector in the meantime. Next, do the cleaning brush with manual, needles, chisel and hammer and other tools. The next object, a cleanup, is at the core of the activities of conservation so they should be able to complete the conservation problems of the purpose until they can last for the long term. The cleaning processed by washing using water soap until completely clean, followed by washing with kaffir lime water to remove the remnants of corrosion and concrete and later distilled water to clean rinsed and dried.

\section{Stabilization/coating}

After all, the process finished, the metal is still prone to further corrosion. Therefore it needs to be done stabilization as soon as possible. The stabilization has done the way coating. The material used is a commonly used coating material, namely candle microcrystalline (microcrystalline wax). The wax is heated so that it melted and added solvent turpentine by comparison 5:100 w/v so that the resulting 
solution $5 \%$ microcrystalline wax. The microcrystalline wax solution further mounted with soft iron cannonballs in materials using a brush. The schematic procedure of experimental in this research can show in Fig.3.

\section{Results And Discussion}

\section{Identification of sample}

Identification of the material weathering iron relics underwater observation is made by visually. The result of the identification of the sample shown in Fig.4. Fig.4. shows identify the weathering and corrosion that occurs on an iron cannonball material that raises concretion (buildup of crust), and the damages cause breaking and destruction of objects. Fig. 4a. shows the metal iron that undergoes weathering and corrosion of a low level. Fig. 4b. shows the metal iron that undergoes weathering and corrosion rates are and start the presence of cracks on ferrous objects. Fig. 4c. shows the metal iron that undergoes weathering and corrosion of metal objects where high levels of iron suffered a split. Fig.3d. shows metal iron that undergoes weathering and corrosion already advanced damage giving rise to a rupture of the destruction of the iron objects.

When iron exposed to the atmosphere, the environment forms different iron-oxides, such as Magnetite $\left(\mathrm{Fe}_{3} \mathrm{O}_{4}\right)$, Hematite $\left(\mathrm{a}-\mathrm{Fe}_{2} \mathrm{O}_{3}\right)$, and maghemite $\left(\mathrm{\gamma}-\mathrm{Fe}_{2} \mathrm{O}_{3}\right)$ [3]. At temperatures higher than $560{ }^{\circ} \mathrm{C}$, the general sequence of the iron-oxide layer (from internal to each surface) is $\mathrm{Fe} / \mathrm{FeO} / \mathrm{Fe}_{3} \mathrm{O}_{4} / \mathrm{Fe}_{2} \mathrm{O}_{3} / \mathrm{O}_{2}$ [4]. The redness of the rust powder and the presence of many cracks and cavities on the surface of the object are indicative of an active corrosion process in progress, causing continuous loss of metals, as well as degradation of mechanical properties [5]. Corrosion of archeological artifacts of iron buried under seawater is an electrochemical process, which involves anodic and cathodic reactions in an aqueous electrolyte environment and biological processes also involve anaerobic bacteria [2]. When iron put into solution, the oxide layer grows slowly so that oxide compounds such as goethite $(\mathrm{a}-\mathrm{FeOOH})$, akaganeit ( $\beta$ $\mathrm{FeOOH})$, and lepidocrocite $(\mathrm{y}-\mathrm{FeOOH})[3,6,7,8,9,10,11,12]$.

\section{Characterization of surface corrosion of iron cannonball material underwater heritage using the handy microscope}

The results of the analysis and characterization of objects using the handy microscope shown in Fig.5. Fig.5. can show the presence of corrosion on materials of iron cannonball underwater cultural remnants can distinguish into two, namely dry active corrosion like in Fig.5a. Fig.5b. shown the wet active corrosion.

The ongoing problem with iron archeology is the continued corrosion after excavation caused by salt accumulation during burial. One way to repair iron material cultural heritage is by immersing objects in solution and waiting for chloride ions to spread out [5]. Weathering of underwater relics generally takes place faster than land-based relics. The rate of weathering of cultural objects underwater can reach 5-10 times faster than objects of cultural heritage on land [1]. The speed of weathering is a result of the 
interaction of the material with water containing salt and biological activity. Weathering chemical reactions occur more quickly in an aqueous medium because the reaction takes place effectively.

\section{Characterization of surface corrosion of iron cannonball material underwater heritage using XRD}

The result of the characterization of surface corrosion using XRD has shown in Fig.6a and Fig.6b. X-ray spectrometry such as XRD, XRF, SEM-EDX/EDS is very suitable for the analysis of inorganic material in the field of conservation and heritage restoration $[13,14,15,16,17]$. Before carrying out conservation must make a diagnosis of the material to be conserved, so it is more appropriate in determining conservation techniques, including consideration of costs and resources [18].

Fig.6. X-ray diffraction clearly show the distinction of compounds contained in corrosion. Fig.6a. generated a peak $2 \theta$ in $26.67^{\circ}$ and $35.11^{\circ}$, while in Fig.6b. is generated peak $2 \theta$ in $26.67^{\circ}$ and $35.17^{\circ}$. The peaks are the peak of akaganeite, supported by research Gil et al. [19] found the presence of akaganeite at the height of $2 \theta=26.68^{\circ}$ and $2 \theta=35.18^{\circ}$. The x-ray diffraction results on a sample of corrosion of iron in the shape of a dried form two types of iron oxide, akaganeite, and lepidocrocite.

The dominant phases of iron artifacts are goethite $(\mathrm{a}-\mathrm{FeOOH})$ and magnetite $\left(\mathrm{Fe}_{3} \mathrm{O}_{4}\right)$. The presence of these types in corrosion products explains the centuries-old good preservation of base metal (iron) and stability after excavation. Corrosion of iron-containing chloride ions, for example, is akaganeite [20]. In addition to artifact material, the corrosion process influenced by environmental pollutants, other archeological materials, geography, microorganisms in the soil, vegetation, land use, soil chemistry, soil physical properties, and the presence or absence of water and air [5].

Fig. 6 shows the $x$-ray diffraction results on corrosion of iron cannonball sample in the way of wet that form four types of iron oxide, i.e. halite $(\mathrm{NaCl})$, akaganeite, briartite iron mineral gray metallic opaque sulfide, $\mathrm{Cu}_{2}(\mathrm{Zn}, \mathrm{Fe}) \mathrm{GeS}_{4}$, famatinite (copper, antimony, sulfide), namely pink-brown mineral containing copper, antimony, and sulfur.

Various artifacts found on the shipwreck, including small arms and ammunition, show their involvement in naval battles [21]. The results showed that the cannonball was made of iron and produced with sand casting molds. Sand found in cavities in cannonballs also studied by petrography [22]. The mineral composition of the results of the characterization using XRD. The result of the investigation of the mineral composition shown in Table 1.

Table 1 Characterization of surface corrosion using XRD

\begin{tabular}{ccccc}
\hline \multirow{2}{*}{ No. } & \multicolumn{2}{c}{ Dried active corrosion } & \multicolumn{2}{c}{ Wet active corrosion } \\
\cline { 2 - 5 } & Mineral & Amounts (\%) & Mineral & Amounts (\%) \\
\hline 1 & Halite & 9.12 & Akaganeite & 96.68 \\
2 & Akaganeite & 89.63 & Lepidocrocite & 3.32 \\
\hline 3 & Famatinite & 0.72 & - & - \\
\hline 4 & Briartite & 0.53 & - & - \\
\hline
\end{tabular}


The iron mineral is akaganeite (III) oxide hydroxide/chloride with the formula: $\mathrm{Fe}^{3+} \mathrm{O}(\mathrm{OH}, \mathrm{Cl})$. Whereas lepidocrocite, also called esmeraldite or hydrohematite is an iron oxide-hydroxide mineral with formula natural occurring $\mathrm{y}-\mathrm{FeO}(\mathrm{OH})$. Table 1 shows the visible presence of significant minerals in the form of akaganiete, which is the most abundant mineral results from corrosion of ferrous metals under seawater. It indicates that the leading causes of corrosion of the metal bottom of the saltwater are chloride ion.

The degradation process of artifacts containing ferrous and non-ferrous, which is induced by contact with aggressive environments such as seawater, will occur more quickly [23]. Analysis by XRD can determine the types of minerals from artifacts to conserved and inhibitors used based on the type of metal: copper and its alloys, iron, and alloys, and other metals (including silver, lead, and zinc) [24]. Information about the morphology, elemental composition, and structure of the crystal makes it possible to determine the constituents of the corrosion layer [25].

The reaction mechanism that occurs in underwater metal corrosion is as follows Hamilton [1]:

Reactions that occur on a more inert metal surface (cathode)

$2 \mathrm{H}_{2} \mathrm{O}+2 \mathrm{e}^{-} \rightarrow \mathrm{H}_{2}+2(\mathrm{OH})^{-}$

Hydroxide ions react with sodium ions in water

$\mathrm{Na}^{+}+\mathrm{OH}^{-} \rightarrow \mathrm{NaOH}$

At the anode the reaction produces iron ions

$\mathrm{Fe}^{2+}+2 \mathrm{e}^{-} \rightarrow \mathrm{Fe}$

$\mathrm{Fe}^{3+}+3 \mathrm{e}^{-} \rightarrow \mathrm{Fe}$

Fe reacts with chloride ions in salt-containing water (the sea)

$\mathrm{Fe}^{2+}+2 \mathrm{Cl}^{-} \rightarrow \mathrm{FeCl}_{2}$

Under water conditions containing oxygen the reaction will continue to form hydroxide:

$\mathrm{FeCl}_{2}+2 \mathrm{NaOH} \rightarrow \mathrm{Fe}(\mathrm{OH})_{2}+2 \mathrm{NaCl}$

The hydroxide compound formed in the oxygen-containing solution will experience a secondary reaction with the formation of corrosion deposits around the metal surface of the anode:

$\mathrm{Fe}+2 \mathrm{e}^{-} \rightarrow \mathrm{Fe}^{2+} \quad$ (Ferrous ion)

$\mathrm{Fe}^{2+}+2 \mathrm{OH}^{-} \rightarrow \mathrm{Fe}(\mathrm{OH})_{2} \quad$ (Ferrous hydroxide) 
$4 \mathrm{Fe}(\mathrm{OH})_{2}+\mathrm{O}_{2} \rightarrow 2 \mathrm{H}_{2} \mathrm{O}+2 \mathrm{Fe}_{2} \mathrm{O}_{3} \cdot \mathrm{H}_{2} \mathrm{O} \quad$ (Hydrated ferric hydroxide)

Secondary reactions involving ferry ions produce other products from corrosion:

$6 \mathrm{Fe}(\mathrm{OH})_{2}+\mathrm{O}_{2} \rightarrow 4 \mathrm{H}_{2} \mathrm{O}+2 \mathrm{Fe}_{3} \mathrm{O}_{4} \cdot \mathrm{H}_{2} \mathrm{O} \quad$ (Green hydrated magnetite)

$\mathrm{Fe}_{3} \mathrm{O}_{4} \cdot \mathrm{H}_{2} \mathrm{O} \rightarrow \mathrm{H}_{2} \mathrm{O}+\mathrm{Fe}_{3} \mathrm{O}_{4} \quad$ (Black magnetite)

\section{The analysis of surface corrosion of iron cannonball material underwater heritage using XRF}

The results of the analysis of surface corrosion of iron cannonball material underwater heritage using XRF shown in Table 2.

Table 2 Characterization of surface corrosion using XRF

\begin{tabular}{ccccc}
\hline \multirow{2}{*}{ No } & \multicolumn{2}{c}{ Dried active corrosion } & \multicolumn{2}{c}{ Wet active corrosion } \\
\cline { 2 - 5 } & Element & Amount (\%) & Element & Amount (\%) \\
\hline 1 & $\mathrm{Cl}$ & 66.603 & $\mathrm{Cl}$ & 64.963 \\
2 & $\mathrm{Fe}$ & 32.105 & $\mathrm{Fe}$ & 24.730 \\
3 & $\mathrm{Ca}$ & 0.320 & - & - \\
4 & $\mathrm{Mn}$ & 0.259 & $\mathrm{Mn}$ & 0.265 \\
5 & $\mathrm{Al}$ & 0.147 & $\mathrm{Al}$ & 0.095 \\
6 & $\mathrm{SiO}_{2}$ & 0.193 & $\mathrm{SiO}_{2}$ & 0.195 \\
7 & $\mathrm{~S}$ & 0.064 & $\mathrm{~S}$ & 0.085 \\
8 & $\mathrm{P}$ & 0.039 & $\mathrm{P}$ & 0.051 \\
9 & $\mathrm{Cd}$ & 0.011 & $\mathrm{Cd}$ & 0.0092 \\
10 & $\mathrm{Sb}$ & 0.0066 & $\mathrm{Sb}$ & 0.0047 \\
11 & $\mathrm{Sn}$ & 0.0041 & $\mathrm{Sn}$ & 0.0047 \\
\hline
\end{tabular}

Table 2. shows the results of the characterization of the corrosion of cannonball iron culture underwater using XRF. Table 2 it can be seen the presence of corrosion contain the most abundant elements are chloride. Table 2 shows indicate that the leading causes of corrosion of cannonball culture underwater remnants (submerged seawater) are chloride ion.

\section{Characterization of surface corrosion of iron cannonball material culture underwater using SEM}

The results of the characterization of surface corrosion of cannonball heritage using SEM (Scanning Electron Microscope) shown in Fig. 7. The existence of corrosion that occurs in cannonball in the form of hollow-cavity and damages the iron material shown in Fig.8.

\section{Passivation/deactivation of material corrosion of cannonball heritage}

Passivation corrosion is the dismissal of corrosion on the object with a particular method. At the passivation in this study, the sample is soaked in a solution of sodium carbonate $5 \%$. The $\mathrm{pH}$ maintained between 11-13 using sodium hydroxide. If the $\mathrm{pH}$ goes down, then it should be raised on the range with a solution of sodium hydroxide, then rinsed with water objects continued wash using distillate water. The purpose of dried and seen its development, if it still happens, then the corrosion process is repeated until corrosion stops. Soaking in this research was conducted for five months, and a mixed solution replaced about four days to a week. Before the process, the passivate not to do cleanup crust or rust. Layers of the 
coating would be a natural protector in the meantime. Next, do a manual cleanup using tools such as brushes, skavel, needles, chisel, hammer and other devices. The cleaning level is adjusted to the level of corrosion of the object if the object is still obviously in shape then be organized as clean as possible. If the form object is already less precise, then the cleanup should be careful so that the part of the purpose did not enter apart at the time of releasing the crust. Not all of the coat should be clean, preferred to maintain/find the form objects. If corrosion is already very advanced, shapes are not visible at all, and then the mechanical cleaning is only on the surface.

Alkali solutions such as sodium hydroxide and potassium hydroxide will remove rust from iron and steel, and when combined with sequestering agents to hold the dissolved iron in solution, they can be very effective, particularly at near-boiling temperatures. Under the $\mathrm{Fe}_{3} \mathrm{O}_{4}$ deposit, the following reactions can occur on the substrate:

$\mathrm{Fe}_{3} \mathrm{O}_{4}+5 \mathrm{H}_{2} \mathrm{O} \rightarrow 3 \mathrm{Fe}(\mathrm{OH})_{3(\mathrm{~s})}+\mathrm{H}^{+}+\mathrm{e}^{-}$

$\mathrm{Fe}_{3} \mathrm{O}_{4}+4 \mathrm{H}_{2} \mathrm{O}+\mathrm{OH}^{-}+2 \mathrm{e}^{-} \rightarrow 3 \mathrm{Fe}(\mathrm{OH})^{3-}$

Next, do the cleaning, the cleaning phase this is the core of the activities of conservation, so should be able to complete the conservation problems of the object until they can last for the long term. Materials were processed cleaning with soapy water, using washing fruit and extract kaffir lime water, rinsed with distilled water. At flushing and drying, at the end of all this stage done flushing to completely clean from chloride solution and used. After completion of the drying, proceed with rinsing. The drying process is carried out by warming in the blazing sun and using a blow dryer.

\section{Stabilization/coating material of iron cannonball underwater heritage}

The coating material used is a microcrystalline wax with variations in concentrations of $5,10,20$, and $50 \%$ with turpentine oil solvents. The use of inhibition of the corrosion process of heritage objects made of iron done by several researchers, namely carboxylic monoacids and ethanol solution [26], acidic solutions from plants [27], coating with carboxylates after the conservation process is completed [28]. Microcrystalline wax used to coat or coating iron metal that has finished passivated so that it is not prone to corrosion again. The results of coating using microcrystalline wax can show in Fig.9. Fig.10. shown the iron cannonball has been conserved and ready to be sent to the museum.

Fig.11. shows some color differences in iron cannonball material coated with the microcrystalline solution. From the results of the image stabilization or coating of iron cannonball material using a 5,10 , 20 , and $50 \%$ microcrystalline wax solution. The results showed that the most suitable solution was because it did not change the color of the sample, namely a microcrystalline wax solution with a concentration of $5 \%$. Iron cannonball material after passive is still prone to further corrosion. Therefore it must be done the stabilization/coating as soon as possible. This stabilization stage is the last stage of the passivated process was complete after all. In this study, the author uses wax microcrystalline $5 \%$ with 
solvent turpentine oil to coating metal iron that has finished passivated, so it is not prone to corrosion returns.

Fig.11. shows a significant difference between the tangible cultural heritage of cultural iron cannonball underwater before conservation (a) and after conservation (b). Fig.11. shown it can conclude that the method of conservation on this research is very suitable to be used in the conservation of iron material underwater. However, this conservation research is research that is not ideal because the iron cannonball material used in the study was far too long in the Mainland has publicly after the adoption of the ocean floor that should iron this cultural heritage material directly conservation after the rapture of the deep sea. The results of the analysis and characterization of iron cannonball material objects linger underwater culture using XRF before and after conservation can be seen in Table 3.

Table 3. shows the after conservation element $\mathrm{Cl}$ and some metals have reacted with $\mathrm{NaOH}$. Element $\mathrm{Cl}$ is the main element causing wet and dry corrosion. After immersion with $5 \% \mathrm{NaOH}$, the $\mathrm{Cl}$ element reacts with $\mathrm{NaOH}$.

$\mathrm{Cl}^{-}+\mathrm{NaOH} \rightarrow \mathrm{NaCl}_{(\mathrm{aq})}+\mathrm{OH}^{-}$

The artifact is soaked for one week with $5 \% \mathrm{NaOH}$, rinsed and distilled water, then cleaned physically with a brush, if the corrosion has not stopped the process of soaking repeated until the corrosion stops. After the corrosion stops, the iron cannonball refined in shape. The reaction between $\mathrm{NaOH}$ and metal in the following example:

$\mathrm{Zn}+2 \mathrm{NaOH} \rightarrow \mathrm{Na}_{2} \mathrm{ZnO}_{2}+\mathrm{H}_{2}$

$\mathrm{Al}^{3+}+3 \mathrm{NaOH} \rightarrow \mathrm{Al}(\mathrm{OH})_{3}+3 \mathrm{Na}^{+}$

$\mathrm{Al}(\mathrm{OH})_{3}+\mathrm{NaOH} \rightarrow 2 \mathrm{Na}^{+}\left[\mathrm{Al}(\mathrm{OH})_{4}\right]^{-}$or

$\mathrm{Al}+\mathrm{NaOH}+\mathrm{H}_{2} \mathrm{O} \rightarrow \mathrm{NaAlO}_{2}+\mathrm{H}_{2}$

Table 3 Characterization of surface corrosion of iron cannonball material using XRF before and after conservation 


\begin{tabular}{|c|c|c|c|c|c|c|c|c|c|c|}
\hline \multirow[t]{2}{*}{ No } & \multicolumn{4}{|c|}{ Before conservation } & \multicolumn{6}{|c|}{ After conservation } \\
\hline & Ele-ment & Amount (\%) & Ele-ment & Amount (\%) & Ele-ment & Amount (\%) & Ele-ment & Amount (\%) & Ele-ment & Amount (\%) \\
\hline 2 & $\mathrm{Fe}$ & 32.105 & $\mathrm{Fe}$ & 24.730 & Co & 0.40 & $\mathrm{Cu}$ & 0.45 & $\mathrm{Mn}$ & 0.44 \\
\hline 3 & $\mathrm{Ca}$ & 0.320 & Mn & 0.265 & $\mathrm{Mn}$ & 0.31 & $\mathrm{Zn}$ & 0.37 & $\mathrm{Cu}$ & 0.12 \\
\hline 5 & $\mathrm{Al}$ & 0.147 & $\mathrm{SiO}_{2}$ & 0.195 & $\mathrm{Zn}$ & 0.17 & $\mathrm{Ti}$ & 0.17 & $\mathrm{Ni}$ & 0.04 \\
\hline 6 & $\mathrm{SiO}_{2}$ & 0.193 & $\mathrm{~S}$ & 0.085 & - & - & - & - & - & - \\
\hline 7 & $\mathrm{~S}$ & 0.064 & $\mathrm{P}$ & 0.051 & - & - & - & - & - & - \\
\hline 8 & $\mathrm{P}$ & 0.039 & $\mathrm{Cd}$ & 0.0092 & - & - & - & - & - & - \\
\hline 9 & $\mathrm{Cd}$ & 0.011 & $\mathrm{Sb}$ & 0.0047 & - & - & - & - & - & - \\
\hline
\end{tabular}

The next step is cleaning with soapy water to remove any residual corrosion. Soap is an alkaline salt of fatty acids so that it will partially to be hydrolyzed by water. Therefore the soap solution in water alkaline.

$\mathrm{CH}_{3}\left(\mathrm{CH}_{2}\right) 16 \mathrm{COONa}+\mathrm{H}_{2} \mathrm{O} \rightarrow \mathrm{CH}_{3}\left(\mathrm{CH}_{2}\right)_{16} \mathrm{COOH}+\mathrm{OH}^{-}+\mathrm{Na}^{+}$

The weak base solution from soapy water can help clean surface corrosion. Iron material cannonball washing with soapy water, and then washed with extract water kaffir lime (weak acid solution). Citric acid is a type of acid that is non-toxic, non-irritating, and environmentally friendly [29]. Citric acid is also easy to find in citrus-like organic substances including citrus (kaffir lime) and lemon (Citrus lemon). The citric acid content contained in kaffir lime is $45.8 \mathrm{~g} / \mathrm{L}$, while the citric acid content contained in lemon is $48.0 \mathrm{~g} / \mathrm{L}$ [30]. Extract water kaffir lime citric acid and ascorbic acid which are weak acids so that it removes impurities on the surface of the ball cannon.

Characterization of iron material ball cannon using XRF before and after conservation (Table 3 ) showed a significant difference in the data. On the object of active corrosion wet and dry before conservation showed the presence of chloride that is the result of corrosion of the iron material, whereas on the object test results after conservation showed very significant differences, in which chloride is no longer detected. From this, it can conclude the process of corrosion on the object was lost and stopped.

\section{Conclusion}

Identification of the degree of weathering and corrosion can be group and sequenced implementation of appropriate handling levels of active corrosion on four levels, namely low, medium, high, and the next. Analysis and characterization using XRD and XRF of surface corroded before conservation identified the existence of akaganeite corrosion product, which is the most important of the corrosion of iron material showed the presence of chloride ions as the cause of corrosion of iron oxyhydroxides which forms a chloride (including akaganeite). Deactivation or passivation use of aqueous $\mathrm{Na}_{2} \mathrm{CO}_{3} 5 \%$ with a pH of 11 13 proved to be able to eliminate concretion and corrosion on the iron cannonball material objects linger 
culture underwater. Stabilization with coating using wax microcrystalline $5 \%$ with solvent turpentine oil is proven according to coat and keep it from further corrosion without damaging the color and shape of the cultural heritage of the iron cannonball material underwater heritage.

\section{Declarations}

\section{Competing Interest}

The authors declare no competing interests.

\section{Author Contributions}

R and M.M.M contribute to design and conception, drafting the article, and final approval of the article. I.S, M.M.M, and N.C contribute to collect the references, drafting the article, preparing all figures and all tables, and discussion. E.T.W contributes to help data analysis and discussion.

\section{Funding}

Authors would like to express appreciation for the funding support from Ministry of Research, Technology and Higher Education (Kemenristekdikti) of Republic Indonesia through World Class Professor Program 2018 Scheme A under Contract No: 123.6/D2.3/KP/2018.

\section{Acknowledgements}

The authors gratefully acknowledge to Borobudur Conservation Office for the sample, chemicals and instrumentation support so this research can be successful.

\section{References}

1. Hamilton DL (1999) Methods of conserving archaeological material from underwater sites. Texas A\&M University: 110

2. North NA (1976) Formation of coral concretions on marine iron. International Journal of Nautical Archaeology 5:253-258

3. Cornell RM, Schwertmann U (2003) The Iron Oxides: Structure, Properties, Reactions, Occurrences and Uses. Wiley

4. Fontana MG (1986) Corrosion Engineering. McGraw-Hill

5. Selwyn L (2004) Overview of archaeological iron: the corrosion problem, key factors affecting treatment, and gaps in current knowledge. Proceedings of metal:294-306

6. Balasubramaniam R, Kumar AVR, Dillmann P (2003) Characterization of rust on ancient Indian iron. Current Science:1546-1555

7. Neff D, Reguer S, Bellot-Gurlet L et al. (2004) Structural characterization of corrosion products on archaeological iron: an integrated analytical approach to establish corrosion forms. Journal of 
Raman Spectroscopy 35:739-745

8. Neff D, Dillmann P, Bellot-Gurlet L et al. (2005) Corrosion of iron archaeological artefacts in soil: characterisation of the corrosion system. Corrosion Science 47:515-535

9. Neff D, Bellot-Gurlet L, Dillmann P et al. (2006) Raman imaging of ancient rust scales on archaeological iron artefacts for long-term atmospheric corrosion mechanisms study. Journal of Raman Spectroscopy: An International Journal for Original Work in all Aspects of Raman Spectroscopy, Including Higher Order Processes, and also Brillouin and Rayleigh Scattering 37:12281237

10. Neff D, Dillmann P, Descostes M et al. (2006) Corrosion of iron archaeological artefacts in soil: Estimation of the average corrosion rates involving analytical techniques and thermodynamic calculations. Corrosion Science 48:2947-2970

11. Balos S, Benscoter A, Pense A (2009) Roman mystery iron blades from Serbia. Materials characterization 60:271-276

12. Barrena MI, De Salazar JMG, Soria A (2008) Roman iron axes manufacturing technology. Nuclear Instruments and Methods in Physics Research Section B: Beam Interactions with Materials and Atoms 266:955-960

13. Emara A-aS, Korany MS (2016) An Analytical Study of Building Materials and Deterioration Factors of Farasan Heritage Houses, and the Recommendations of Conservation and Rehabilitation (German House Case Study). Procedia-Social and Behavioral Sciences 216:561-569

14. Theile JM, Guarda S, Croquevielle E (2014) Analysis, conservation and restoration of the metal threads used in Latin American colonial saints' robes. In, p 501-513

15. Watkinson D (2013) Conservation, corrosion science and evidence-based preservation strategies for metallic heritage artefacts. In: Corrosion and Conservation of Cultural Heritage Metallic Artefacts. Elsevier, p 9-36

16. Van Grieken R, Worobiec A (2011) X-ray spectrometry for preventive conservation of cultural heritage. Pramana 76:191-200

17. Fernandes R, Van Os BJH, Huisman HDJ (2013) The use of Hand-Held XRF for investigating the composition and corrosion of Roman copper-alloyed artefacts. Heritage Science 1:30

18. Argyropoulos V, Boyatzis S, Giannoulaki M et al. (2013) The role of standards in conservation methods for metals in cultural heritage. In: Corrosion and Conservation of Cultural Heritage Metallic Artefacts. Elsevier, p 478-517

19. Gil MLA, Santos A, Bethencourt M et al. (2003) Use of X-ray and other techniques to analyse the phase transformation induced in archaeological cast iron after its stabilisation by the electrolytic method. Analytica chimica acta 494:245-254

20. Jegdić B, Polić-Radovanović S, Ristić S et al. (2012) Corrosion of archaeological artefact made of forged iron. Metallurgical and Materials Engineering 18:233-240

21. Cvikel D, Kahanov YA (2009) The Akko 1 shipwreck, Israel: the first two seasons. International Journal of Nautical Archaeology 38:38-57

Page 13/23 
22. Mentovich ED, Schreiber DS, Goren Y et al. (2010) New insights regarding the Akko 1 shipwreck: a metallurgic and petrographic investigation of the cannonballs. Journal of Archaeological Science 37:2520-2528

23. Angelini E, Grassini S, Tusa S (2013) Underwater corrosion of metallic heritage artefacts. In: Corrosion and conservation of cultural heritage metallic artefacts. Elsevier, p 236-259

24. Cano E, Lafuente D (2013) Corrosion inhibitors for the preservation of metallic heritage artefacts. In: Corrosion and conservation of cultural heritage metallic artefacts. Elsevier, p 570-594

25. Neff D, Reguer S, Dillmann P (2013) Analytical techniques for the study of corrosion of metallic heritage artefacts: from micrometer to nanometer scales. In: Corrosion and conservation of cultural heritage metallic artefacts. Elsevier, p 55-81

26. Mohammed EaA, De Keersmaecker $M$, Adriaens A (2016) Inhibition of the corrosion of iron heritage objects after treatment with long-chain monocarboxylic acids in ethanolic solutions. Progress in Organic Coatings 101:225-232

27. Chellouli M, Chebabe D, Dermaj A et al. (2016) Corrosion inhibition of iron in acidic solution by a green formulation derived from Nigella sativa L. Electrochimica Acta 204:50-59

28. Abrantes LM, Melato Al (2013) Coatings including carboxylates for the preservation of metallic heritage artefacts. In: Corrosion and Conservation of Cultural Heritage Metallic Artefacts. Elsevier, $p$ 518-539

29. Liu D, Suo Y, Zhao J et al. (2018) Effect of demulsification for crude oil-in-water emulsion: comparing $\mathrm{CO} 2$ and organic acids. Energy \& fuels 32:757-764

30. Penniston KL, Nakada SY, Holmes RP et al. (2008) Quantitative assessment of citric acid in lemon juice, lime juice, and commercially-available fruit juice products. Journal of Endourology 22:567-570

\section{Figures}




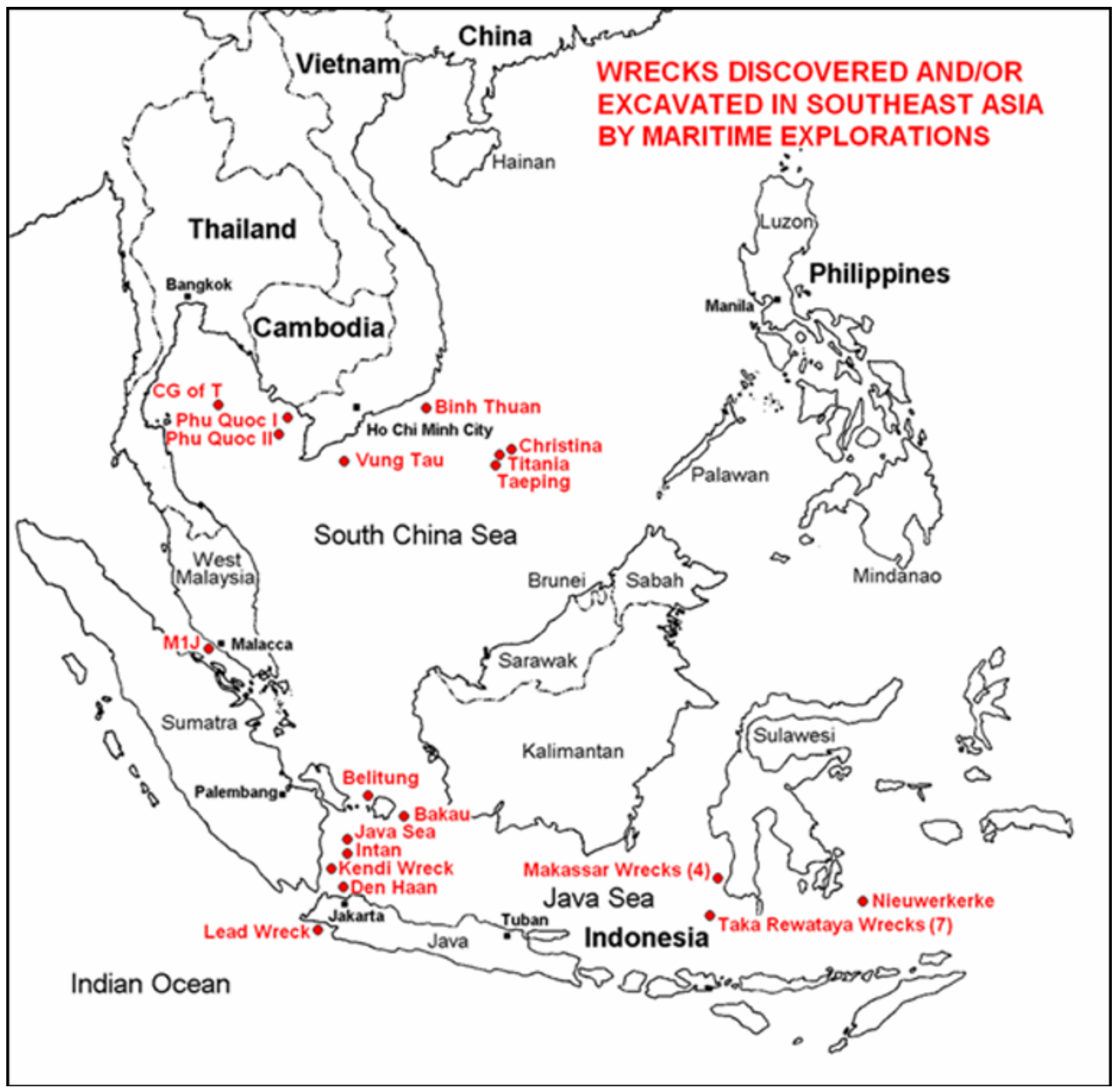

Figure 1

Geological location of shipwreck materials iron cannonball 


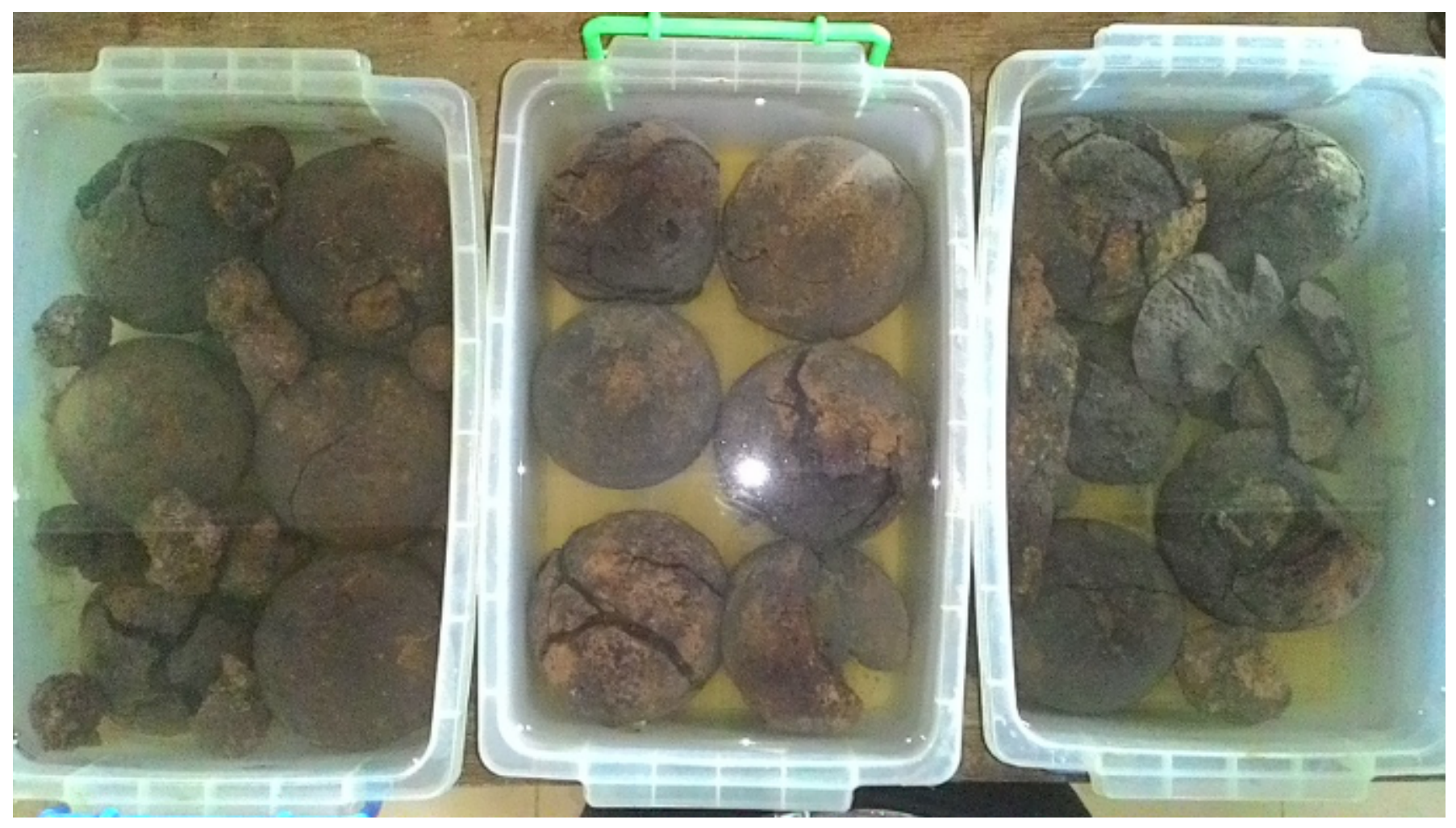

Figure 2

The cannonball material iron immersed in a solution of sodium carbonate $5 \%$ for one week 


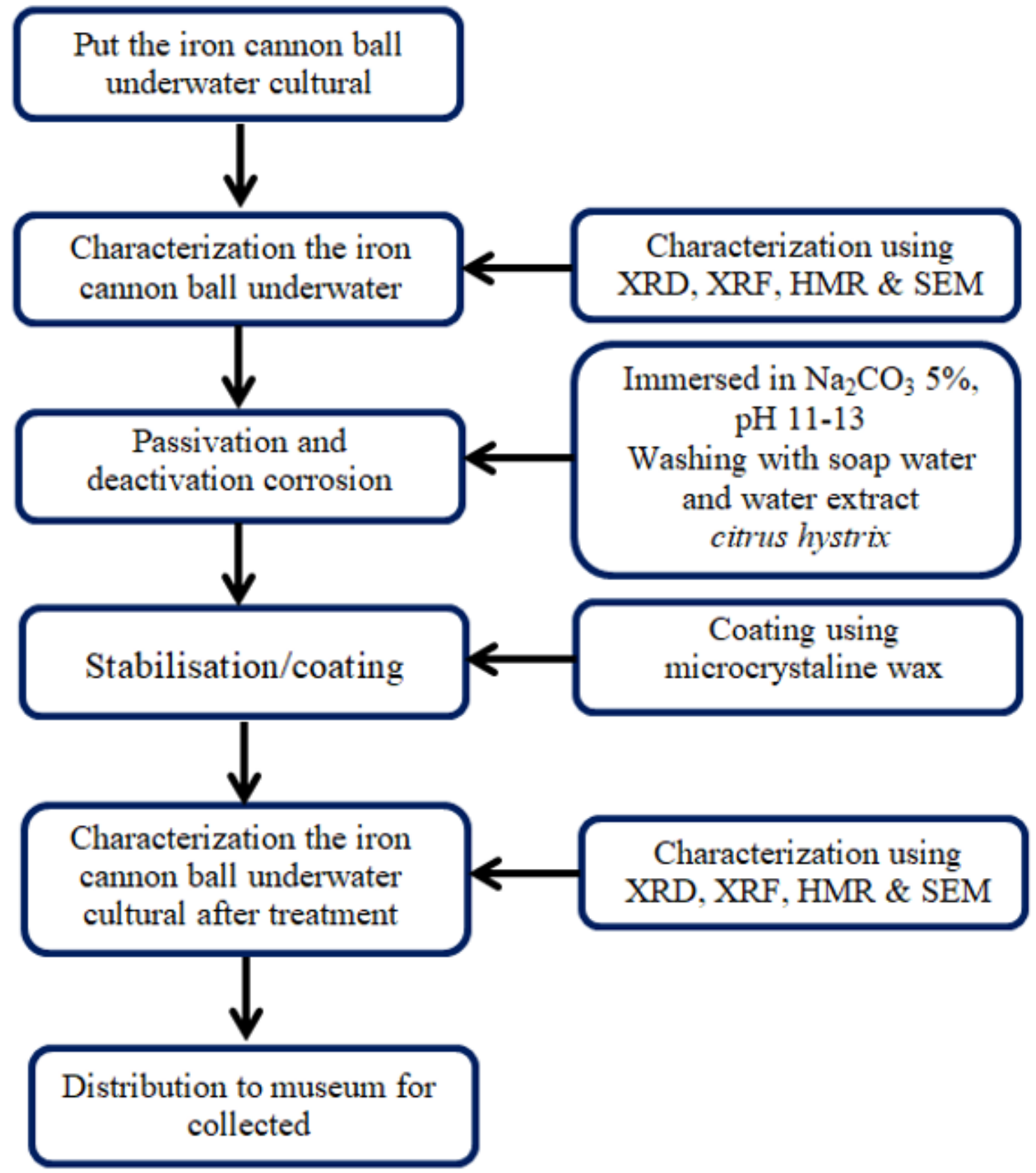

Figure 3

Schematic procedure of the conservation of underwater cannonball heritage 


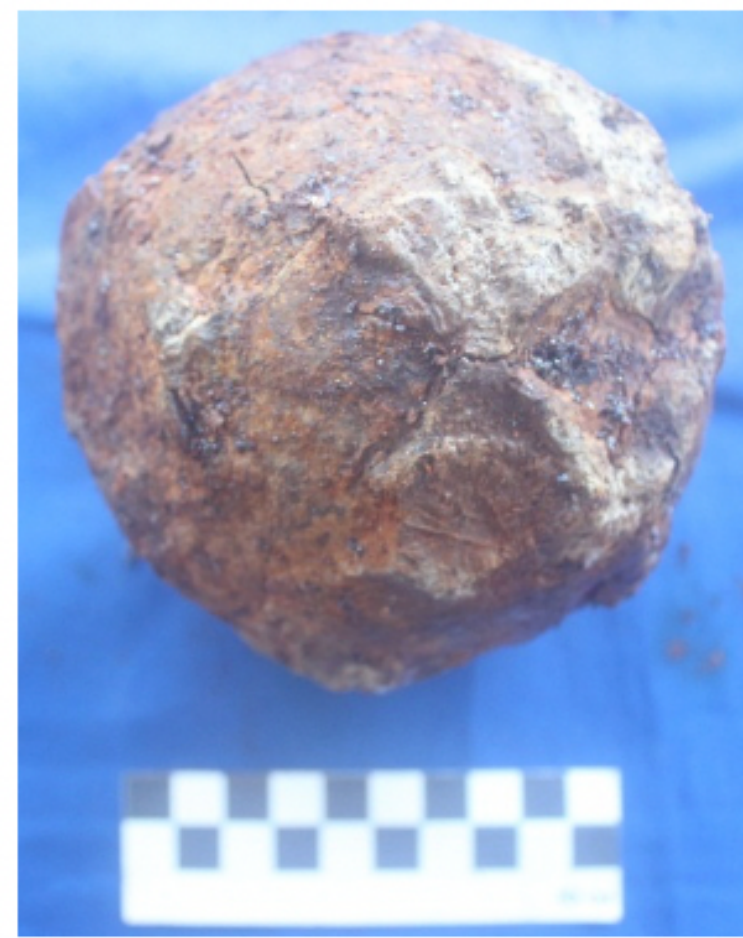

a)

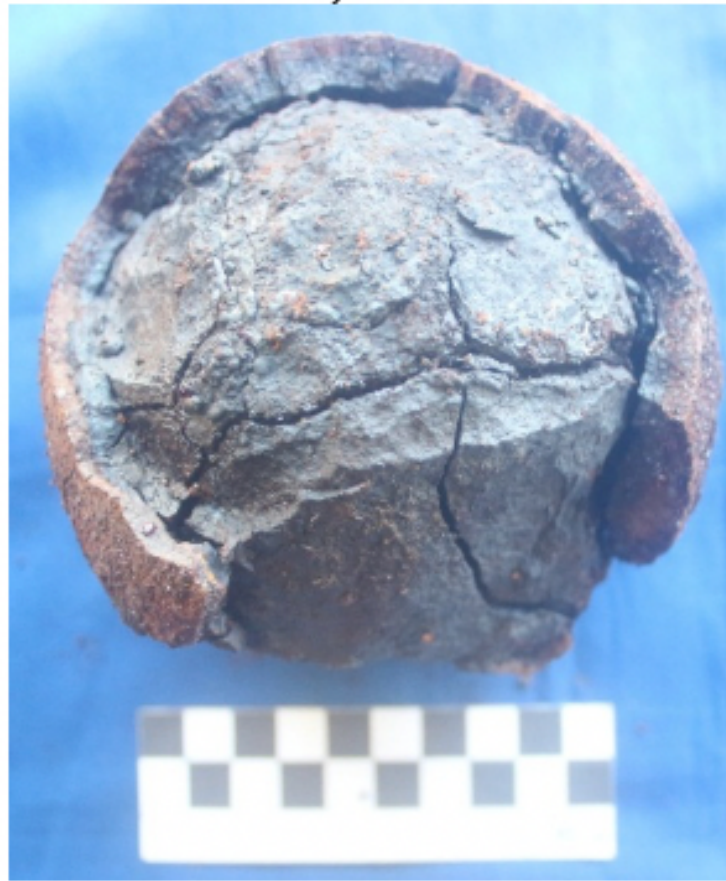

c)

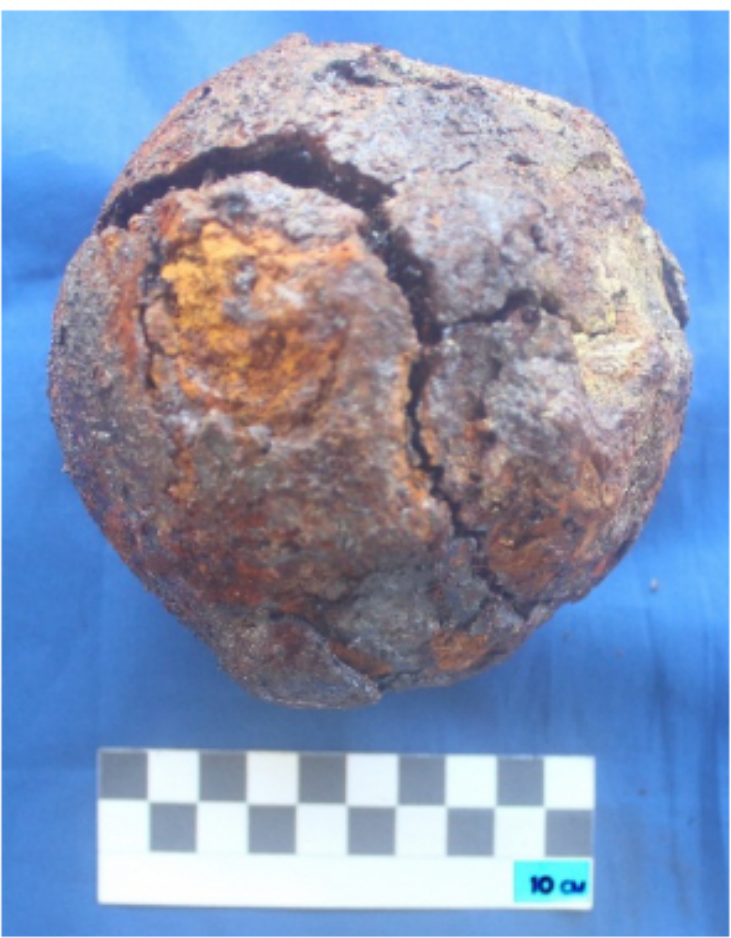

b)

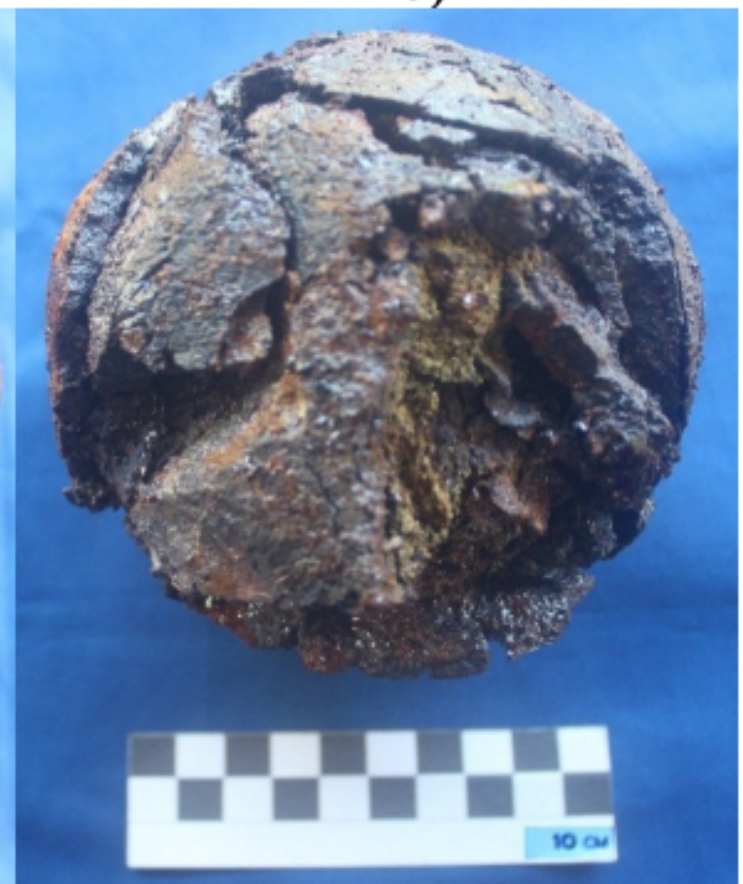

d)

\section{Figure 4}

Weathering and corrosion of the iron cannonball material (a) low, (b) medium, (c) high, (d) advance. 


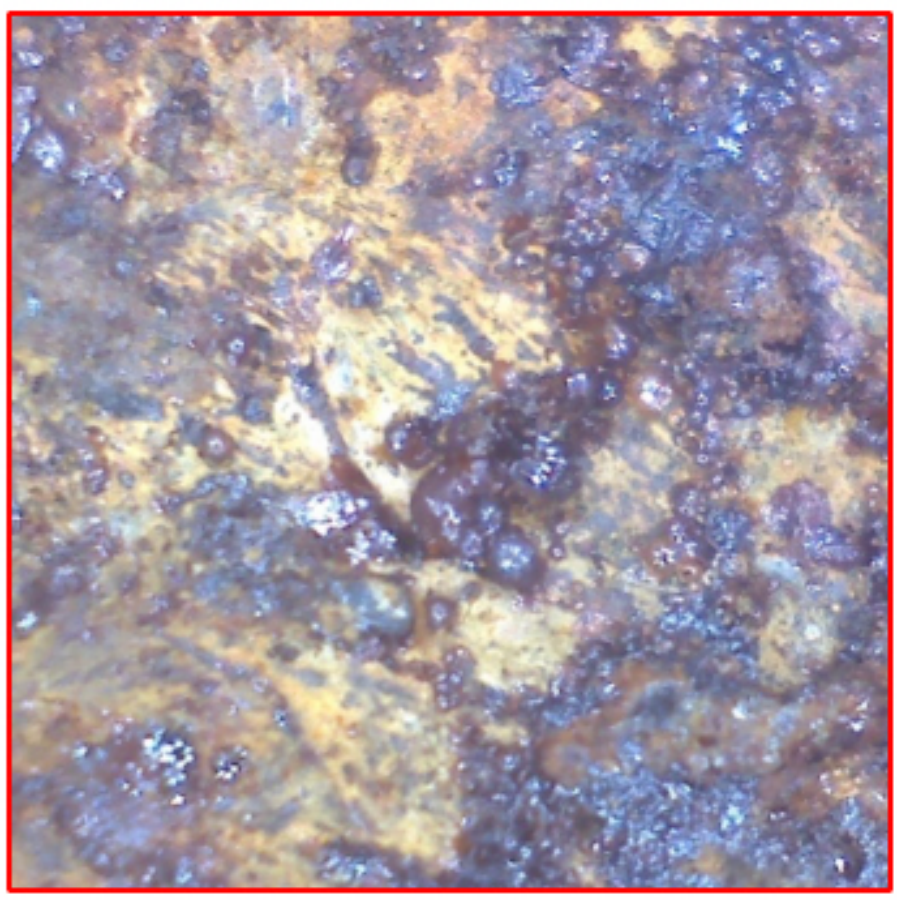

a)

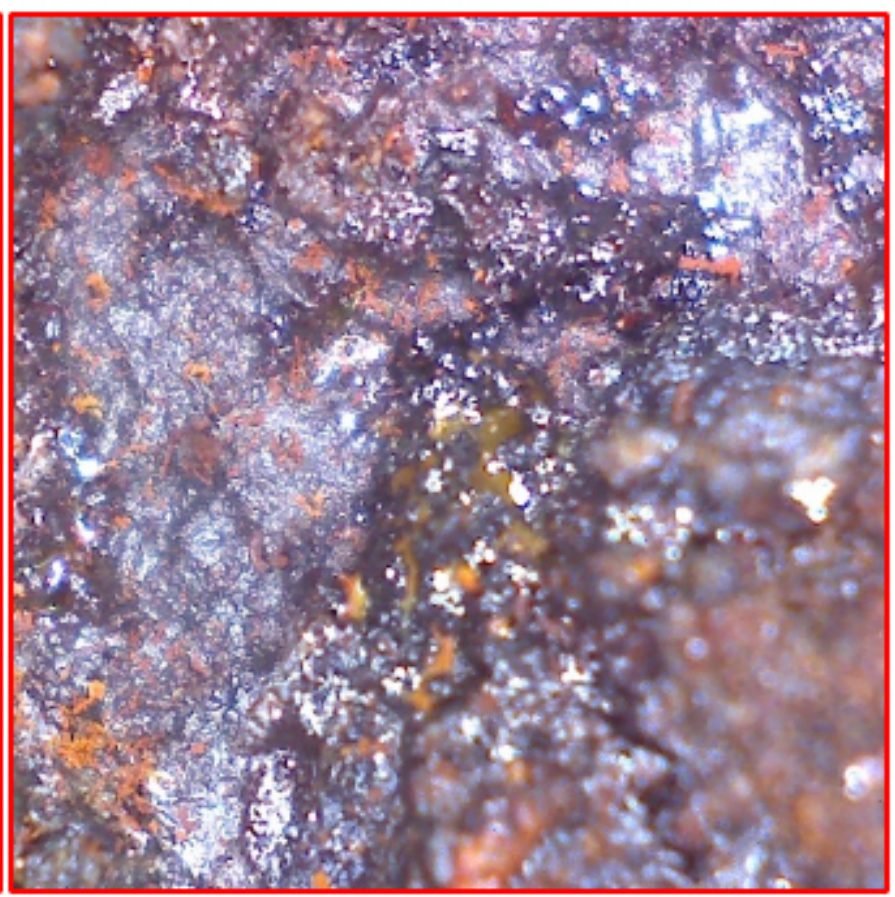

b)

\section{Figure 5}

The handy microscope image the corrosion of iron cannonball material (a) dried active corrosion, (b) wet active corrosion 
a)

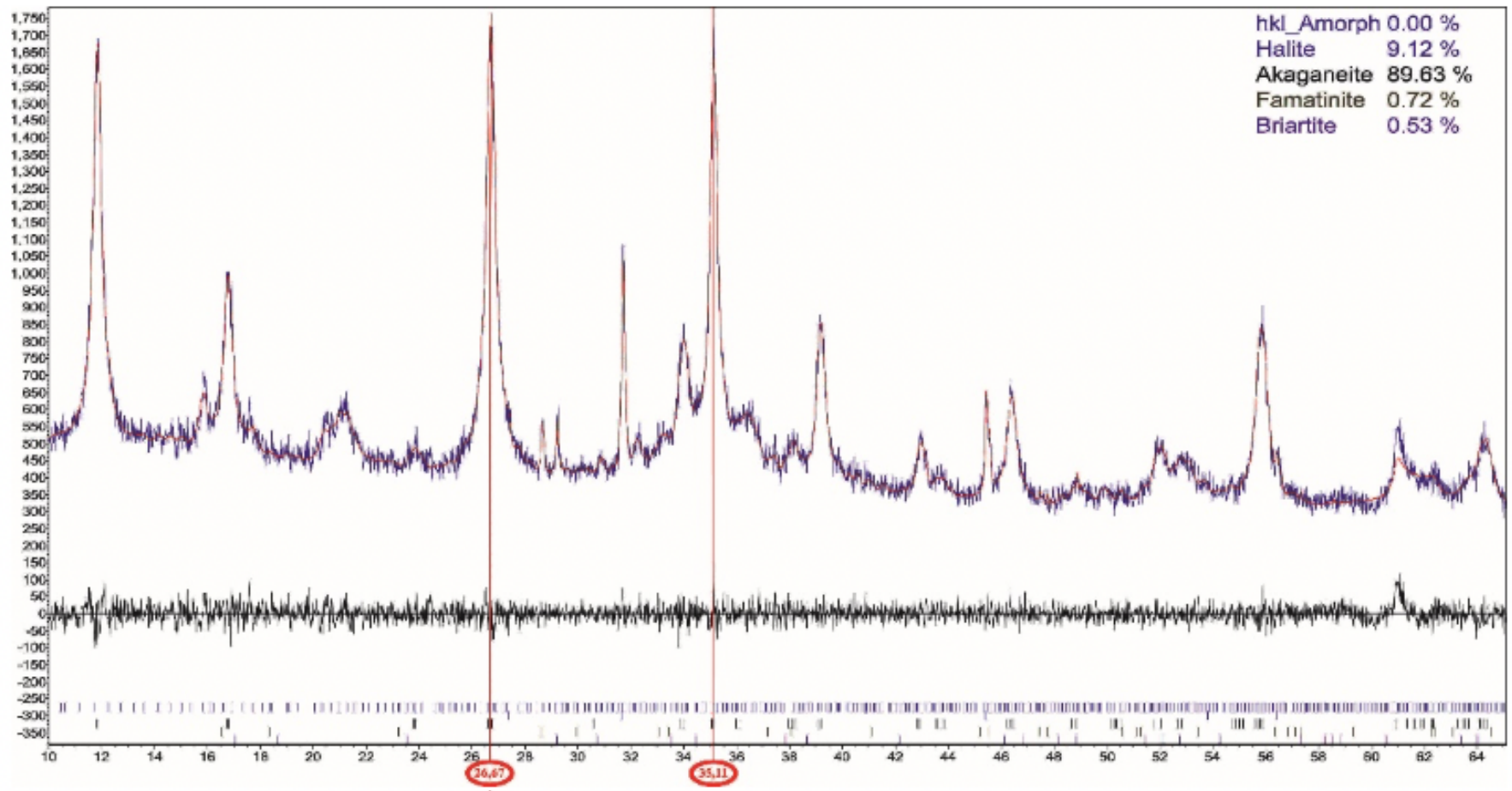

b)

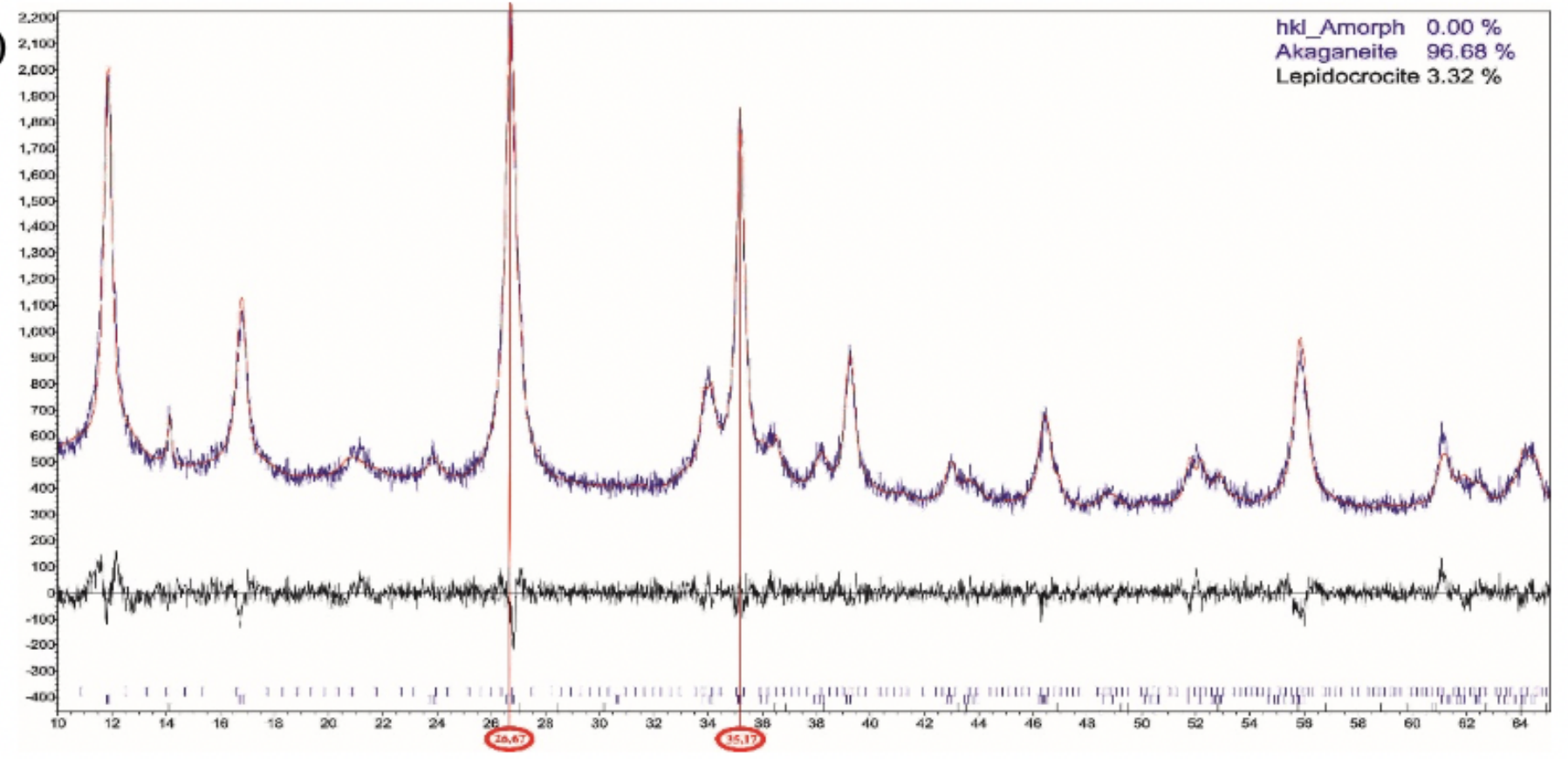

Figure 6

X-ray diffraction the cannonball material underwater heritage (a) dried active corrosion (b) wet active corrosion 


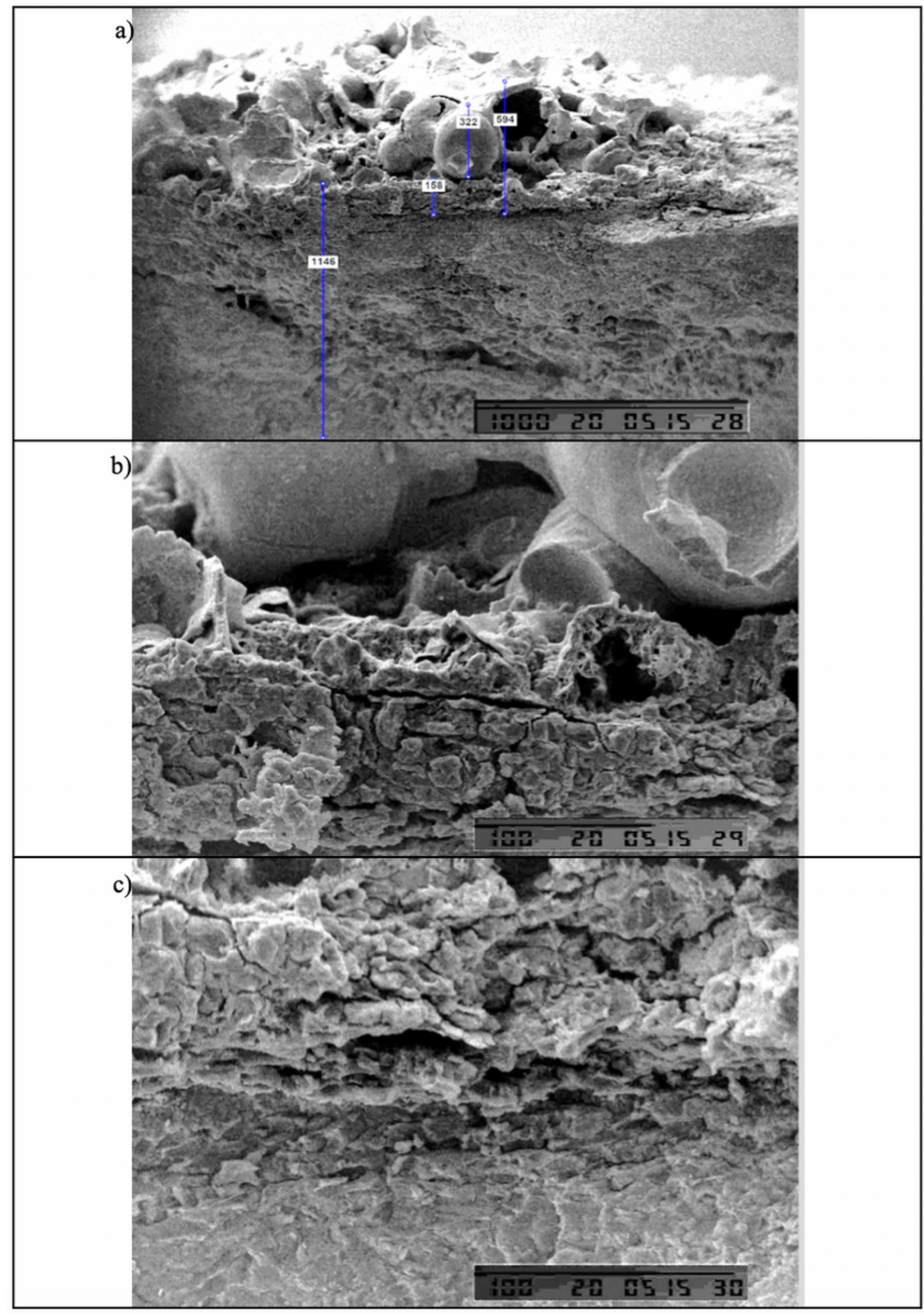

\section{Figure 7}

SEM image from the cannonballs with the magnification (a) 50x (b) 350x and (c), 500 


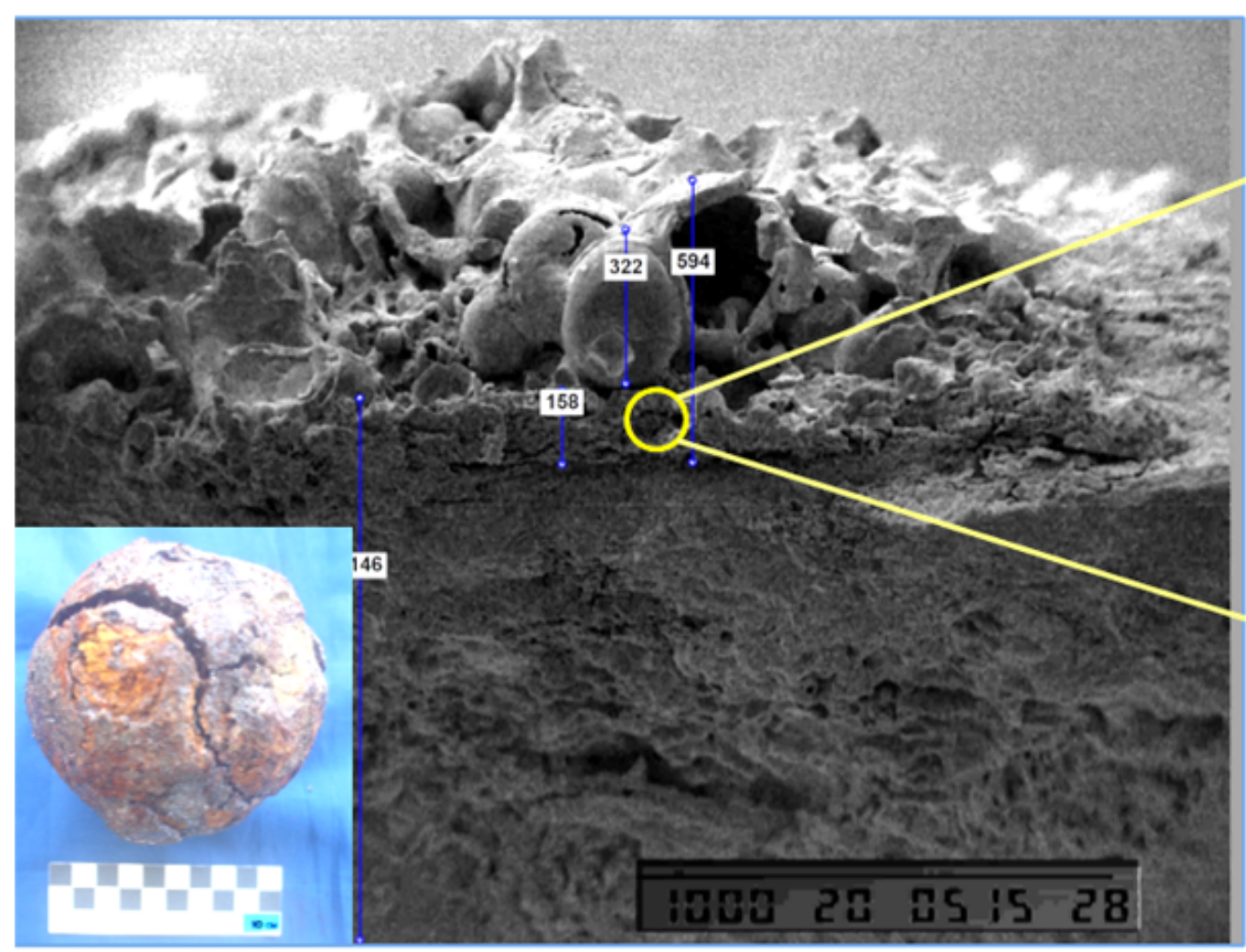

a)

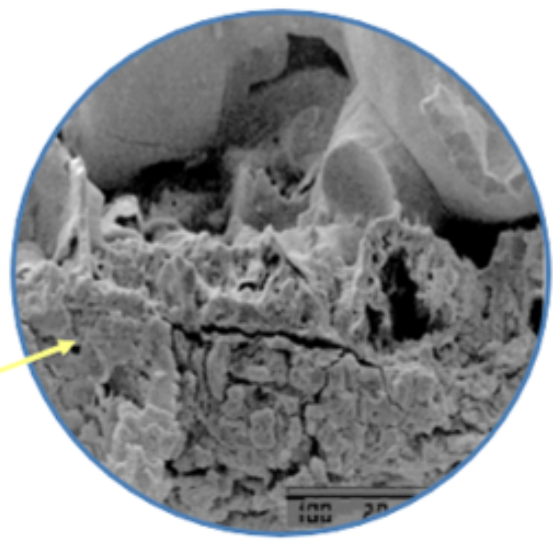

b)

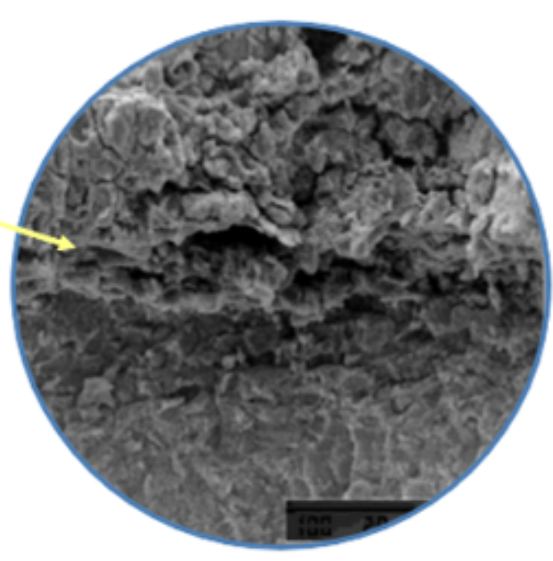

c)

\section{Figure 8}

SEM image from the cannonballs at the point of rust growth with magnification (a) 50x (b) $350 x$ and (c) $500 x$

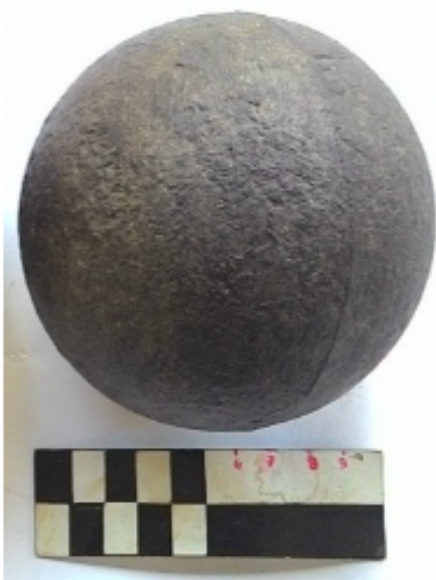

(a)

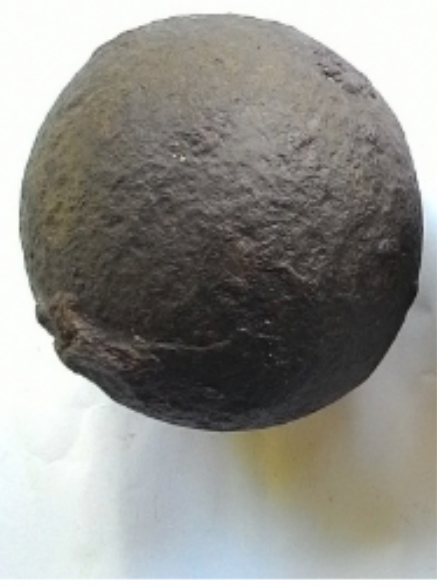

(b)

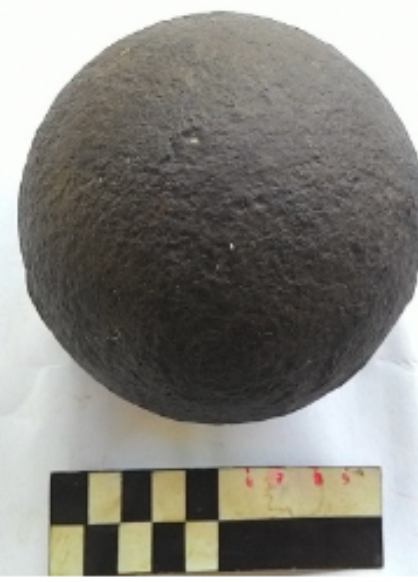

(c)

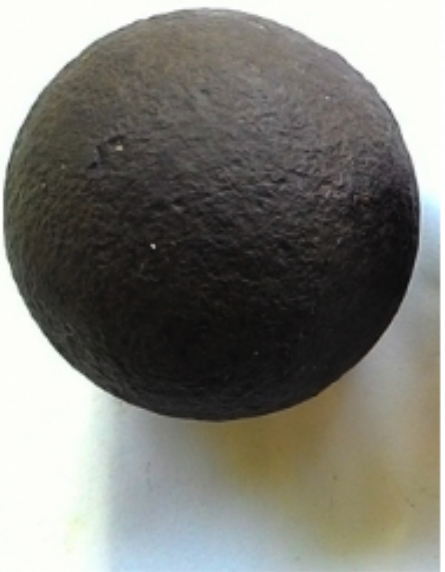

(d)

Figure 9

Layered iron cannonball using microcrystalline wax with concentrations (a) 5 (b) 10 (c) 20 and (d) 50\% 


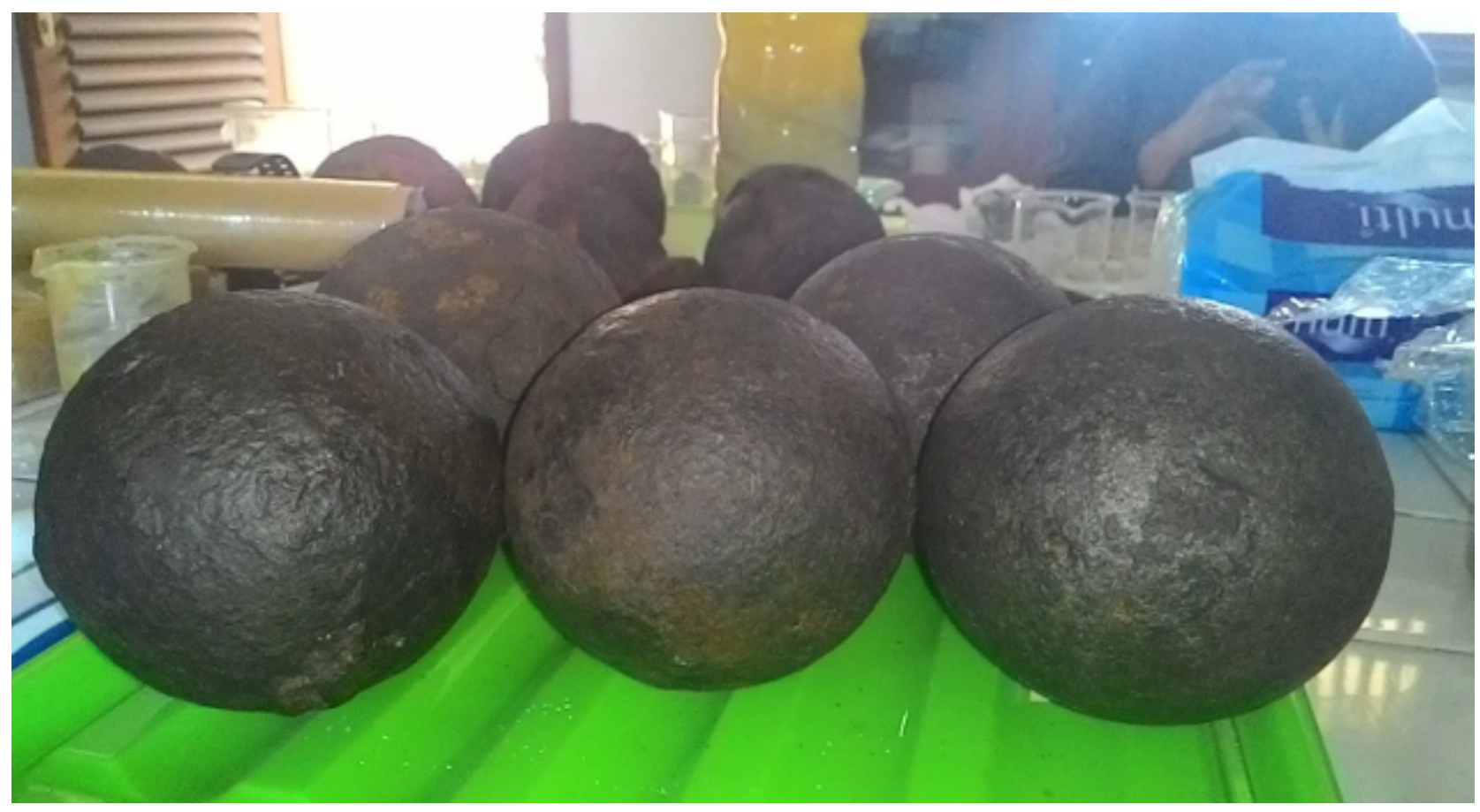

Figure 10

The iron cannonball has been conserved and ready sent to the museum
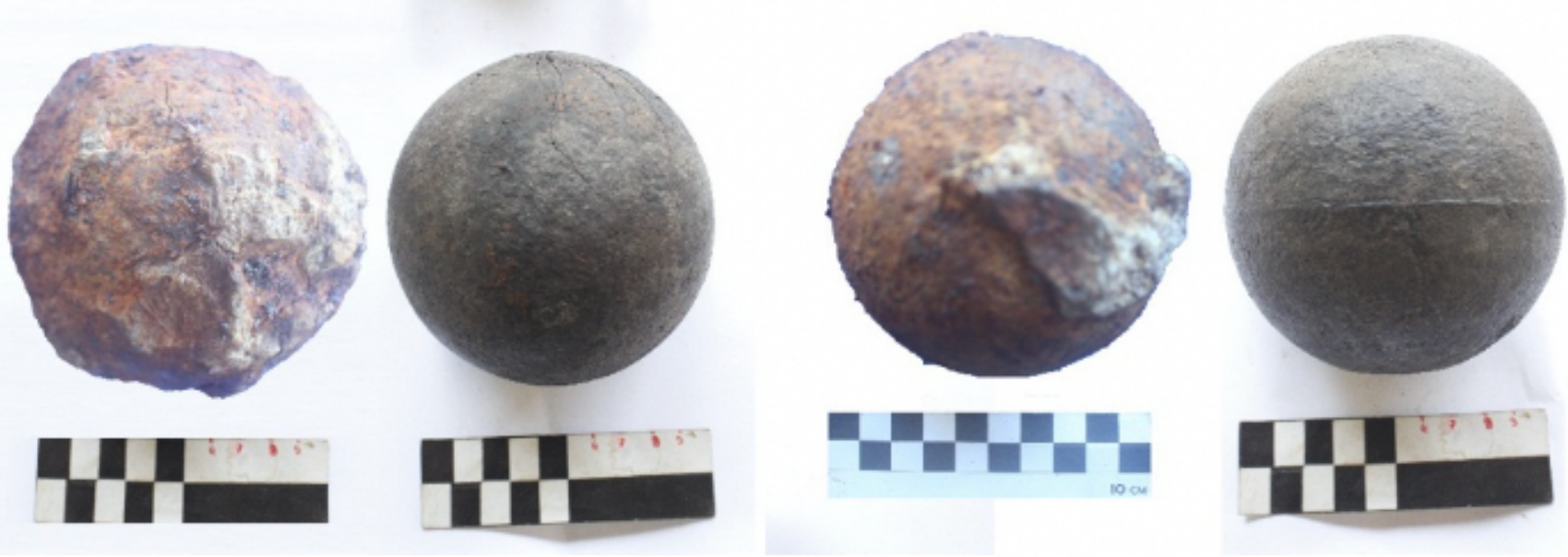

a)

b)

Figure 11

Cannonballs (a) before and ( $b$ ) after conservation 